\title{
LOS NIVELES SÉRICOS DE ADENOSIN DEAMINASA Y ÁCIDO ÚRICO SE CORRELACIONAN EN PACIENTES GESTANTES CON TRASTORNOS HIPERTENSIVOS *
}

\author{
Desiree Vilchez P. 1, Mary Carmen Pérez-Aguilar², Samir Saba K. 1, Rafael \\ Bonfante-Cabarcas. ${ }^{2}$
}

\footnotetext{
1 Servicio IV de Ginecología y Obstetricia, Hospital Central Universitario Antonio María Pineda, ${ }^{2}$ Unidad de Bioquímica, Decanato de Ciencias de la Salud Dr. Pablo Acosta Ortiz, Universidad Centroccidental Lisandro Alvarado, BarquisimetoVenezuela.

* Financiamiento: Proyecto 001-ME-2005
}

\section{RESUMEN}

Objetivo: Evaluar los niveles séricos de la enzima adenosin-deaminasa (ADA) en pacientes gestantes normales y en pacientes con trastornos hipertensivos del embarazo, para determinar su relación con la gravedad del trastorno hipertensivo y con los niveles séricos de marcadores bioquímicos. Método: Se evaluaron pacientes con preeclampsia leve, preeclampsia grave, hipertensión gestacional y embarazadas sanas $(n=10$ por cada grupo). Se determinaron los niveles de ADA, ácido úrico, creatinina, amonio y enzimas hepáticas. Resultados: Se detectó una elevación en los niveles séricos de ADA en pacientes con preeclampsia y con hipertensión gestacional, en comparación con aquellas que cursaron con un embarazo normal. Los niveles ADA se correlacionaron positivamente con los niveles de ácido úrico y creatinina, más no con la severidad clínica. A su vez los niveles de ácido úrico se asociaron con la creatinina sérica y con la severidad clínica de los trastornos hipertensivos. Se encontró un incremento en los niveles de amonio en los pacientes con preeclampsia, el cual no se correlacionó con los otros marcadores bioquímicos, mientras que los niveles de TGO, TGP y LDH se encontraron significativamente elevados en la preeclampsia grave. Conclusión: Este estudio permite relacionar la actividad de ADA con los trastornos hipertensivos del embarazo, los niveles elevados de amonio con la preeclampsia y los niveles de ácido úrico, TGO, TGP y LDH con la severidad de los trastornos hipertensivos.

\section{PALABRAS CLAVE: Adenosin deaminasa, preeclampsia, hipertensión gestacional, ácido úrico, amonio}

\section{SUMMARY}

Objective: To evaluate serum levels of the enzyme adenosine deaminase (ADA) in normal pregnant and patients with hypertensive disorders induced by pregnancy, in order to determine their relationship with the severity of the hypertensive disorder and with serum biochemical markers. Method: We evaluated patients with mild preeclampsia, severe preeclampsia, gestational hypertension and healthy pregnancy $(n=10$ per group). We determined the serum levels of ADA, uric acid, creatinine, ammonia and liver enzymes. Results: In patients with preeclampsia and gestational hypertension we detected a rise in serum ADA as compared with those who had undergone a normal pregnancy. ADA levels were positively correlated with uric acid and creatinine serum levels, but not with clinical severity. Uric acid levels were associated with serum creatinine 
and the clinical severity of hypertensive disorders. We also found an increase in ammonia levels in patients with preeclampsia, which did not correlate with other biochemical markers, while the levels of SGOT, SGPT, and LDH were significantly elevated in severe preeclampsia. Conclusion: This study establishes a link between the activity of ADA with hypertensive disorders of pregnancy, high levels of ammonium with preeclampsia and uric acid, SGOT, SGPT and LDH levels with the severity of hypertensive disorders.

\section{KEY WORDS: Adenosine deaminase, preeclampsia, gestational hypertension, uric acid, ammonia}

\section{INTRODUCCIÓN}

La preeclampsia se presenta en todas las poblaciones con una incidencia general entre $2-8 \%$ (1), en Venezuela oscila entre $1,6-6,2 \%$ (2). Aunque la etiología y la patogénesis de la preeclampsia no está completamente comprendida, algunas observaciones sugieren que la invasión deficiente del trofoblasto hacia las arterias espirales origina una isquemia placentaria (3), que desencadena la liberación de adenosina, la cual tiene acción inmunomoduladora en los procesos inflamatorios y protege contra las consecuencias deletéreas de la isquemia-reperfusión (4).

Los niveles de adenosina están regulados por la actividad de la enzima adenosin-deaminasa (ADA), ya que la inducción de la actividad ADA es una adaptación metabólica a los elevados niveles de adenosina durante la hipoxia (5). La elevación en los niveles séricos de ADA en pacientes preeclámpticas ha sido reportada por diversos autores (6-9), estando asociada con procesos patogénicos relacionados con la peroxidación lipídica y con un incremento en la respuesta inmune mediada por células.

El objetivo de este estudio es evaluar la actividad ADA en suero de pacientes con preeclampsia e hipertensión gestacional, para correlacionar su actividad con la severidad del cuadro hipertensivo y con los niveles séricos de marcadores bioquímicos propios de la preeclampsia.

\section{PACIENTES Y MÉTODOS}

Población y muestra. Fueron seleccionadas 40 pacientes que ingresaron al Servicio IV de Ginecología y Obstetricia del Hospital Central Universitario Antonio María Pineda de la ciudad de Barquisimeto-Venezuela, entre noviembre de 2008 y marzo de 2009, con motivo de cesáreas electivas o para tratamiento de cuadro hipertensivo. Los pacientes se dividieron en: grupo control constituido por 10 pacientes que cursaron con un embarazo normal, 10 con preeclampsia leve, 10 con preeclampsia grave y 10 con hipertensión gestacional.

Se incluyeron en este estudio pacientes con feto único de anatomía normal, no fumadoras y sin evidencia de infecciones recientes. Se excluyeron aquellas que presentaran algunas de las siguientes condiciones: enfermedades renales o hepáticas, tuberculosis asociada, cáncer, procesos pulmonares o pleurales, procesos infecciosos o consumo de antioxidantes.

La preeclampsia leve fue definida como la combinación de cifras tensionales entre $140 / 90 \mathrm{mmHg}$ y $160 / 105 \mathrm{mmHg}$, proteinuria mayor a $300 \mathrm{mg}$ y menor a $5 \mathrm{~g}$ en 24 horas, edema y ausencia de disfunción orgánica. La preeclampsia grave se definió como presión arterial sistólica mayor a 160/110 $\mathrm{mmHg}$, proteinuria mayor a $5 \mathrm{~g}$ en 24 horas, alteraciones del sistema nervioso central, trombocitopenia o anemia hemolítica microangiopática. La hipertensión gestacional fue diagnosticada, cuando las lecturas de la presión arterial fueron de 140/90 $\mathrm{mmHg}$ después de las veinte semanas de embarazo y sin proteinuria.

Todas las pacientes otorgaron consentimiento informado, que fue aprobado por el comité de ética del Decanato de Ciencias de la Salud y del Hospital Central Universitario Antonio María Pineda. En el caso de las menores de edad, se solicitó el consentimiento al representante legal.

Se tomaron muestras de sangre de la vena antecubital, que fueron colocadas en tubos de ensayo con y sin anticoagulante para ejecutar los exámenes complementarios de hemoglobina, hematocrito, recuento de leucocitos y plaquetas, creatinina, úrea, bilirrubina total y fraccionada, proteínas totales y fraccionadas, ácido úrico, lactato deshidrogenasa y glicemia, adicionalmente se recolectó orina de 24 horas para determinar proteinuria y uroanálisis.

Determinación de amonio y ADA. Se obtiene 5-7 $\mathrm{mL}$ de sangre sin anticoagulante, colocada a temperatura ambiente por al menos dos horas. Se centrifugaron a $3000 \mathrm{rpm}$ por 30 minutos. El suero fue separado y almacenado a menos $20^{\circ} \mathrm{C}$ hasta su procesamiento. Luego las muestras fueron descongeladas progresivamente y la actividad ADA fue 
medida espectrofotométricamente, empleando el método colorimétrico descrito por Giusti y Galanti (10). De igual manera se determinó la concentración de amonio formado, ensayando la muestra de suero en ausencia de adenosina.

Análisis estadístico. Todos los resultados son presentados en promedios \pm error estándar $(E E)$. Se realizó ANOVA de una vía y el postest de Dunnet para establecer si existían diferencias significativas entre los grupos, considerando como estadísticamente significativo un valor $p<0,05$. Los análisis fueron realizados utilizando el programa GraphPad Prism 4.

\section{RESULTADOS}

El promedio de edad de las pacientes fue $26,2 \pm$ 1,3 años (rango: 14-42 años) (Figura 1A). La edad de las pacientes con preeclampsia leve fue significativamente mayor al ser comparada con las pacientes de los otros grupos (Tabla I).

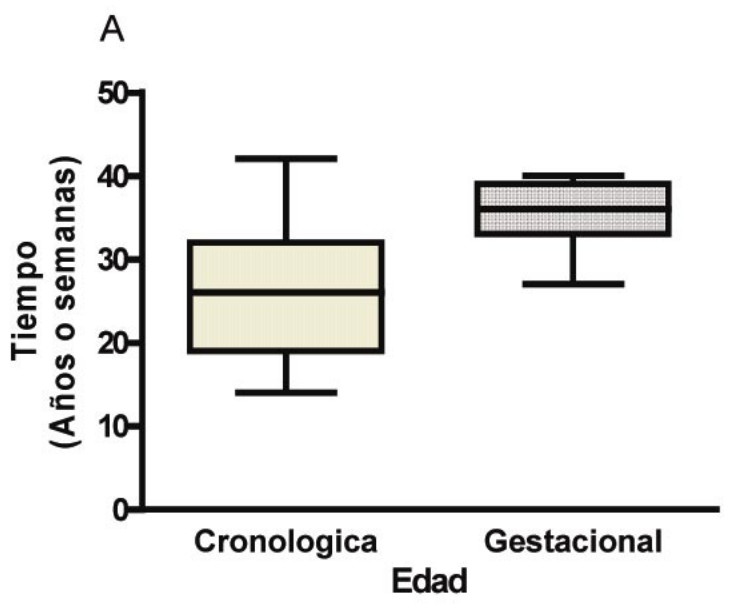

Figura $1 A$. Edad y clínica de los pacientes con embarazos normales y con trastornos hipertensivos. En A se muestra la edad cronológica y gestacional de los pacientes.

Tabla I

CARACTERÍSTICAS CLÍNICAS Y PARACLÍNICAS DE LAS PACIENTES CON TRASTORNOS HIPERTENSIVOS DEL EMBARAZO

\begin{tabular}{lcccc}
\hline & $\begin{array}{c}\text { Control } \\
\text { sano }\end{array}$ & $\begin{array}{c}\text { Hipertensión } \\
\text { gestacional }\end{array}$ & $\begin{array}{c}\text { Preeclampsia } \\
\text { leve }\end{array}$ & $\begin{array}{c}\text { Preeclampsia } \\
\text { grave }\end{array}$ \\
\hline Edad materna (años) & $23,11 \pm 2,59$ & $26,91 \pm 2,44$ & $32,10 \pm 2,83^{\star}$ & $22,50 \pm 1,52$ \\
Edad gestacional (semanas) & $38,5 \pm 0,31$ & $34,1 \pm 1,15^{\star}$ & $34,20 \pm 1,18^{\star}$ & $34,5 \pm 1,35$ \\
PAS (mmHg) & $110,0 \pm 2,1$ & $142 \pm 2,49^{*}$ & $156 \pm 2,67^{\star}$ & $163 \pm 2,13^{\star}$ \\
PAD (mmHg) & $69,0 \pm 2,77$ & $93 \pm 1,53^{*}$ & $102 \pm 1,33^{*}$ & $105 \pm 2,24^{*}$ \\
Hemoglobina (g/dL) & $11,54 \pm 0,35$ & $11,78 \pm 0,23$ & $11,63 \pm 0,27$ & $11,54 \pm 0,35$ \\
Hematocrito (\%) & $35,64 \pm 1,02$ & $35,31 \pm 1,27$ & $33,34 \pm 0,96$ & $36,78 \pm 1,72$ \\
Cuenta blanca (mm $\left.{ }^{3}\right)$ & $9250 \pm 736$ & $8210 \pm 665$ & $9685 \pm 952$ & $11070 \pm 1297$ \\
Creatinina (mg/dL) & $0,53 \pm 0,04$ & $0,56 \pm 0,04$ & $0,58 \pm 0,06$ & $0,79 \pm 0,11$ \\
AU (mg/dL) & $2,25 \pm 0,14$ & $3,33 \pm 0,34$ & $5,4 \pm 0,67^{*}$ & $5,52 \pm 0,98^{*}$ \\
TGO (U/L) & $16,93 \pm 3,9$ & $18,31 \pm 0,83^{\star}$ & $20,51 \pm 3,0$ & $72,56 \pm 28,28^{\star}$ \\
TGP (U/L) & $15,39 \pm 3,21$ & $21,07 \pm 2,5$ & $22,06 \pm 3,63$ & $60,97 \pm 18,41^{*}$ \\
LDH (U/L) & $160,9 \pm 12,9$ & $193,7 \pm 19,97$ & $184,9 \pm 15,47$ & $356,2 \pm 44,18^{*}$ \\
\hline
\end{tabular}

Presión arterial sistólica (PAS), Presión arterial diastólica (PAD), Ácido úrico (AU), Transaminasa Glutámico Pirúvica (TGO), Transaminasa Glutámico Oxaloacética (TGP), Lactato deshidrogenasa (LDH). ${ }^{*} \mathrm{p}<0,05$ al ser comparados con control sano. 
La edad gestacional al momento del diagnóstico osciló entre 27 y 40 semanas, con un promedio de $35,5 \pm 0,6$ semanas (Figura 1A). Las pacientes con embarazos normales y con hipertensión gestacional desarrollaron trabajo de parto o fueron sometidas a cesáreas programadas entre las 36 y las 40 semanas de gestación, cuando cursaban con embarazos a término, mientras que las pacientes con preeclampsia leve y preeclampsia grave fueron interrumpidas antes de las 36 semanas. Los síntomas y signos clínicos más frecuentemente observados fueron cefalea, edema, hiperreflexia, escotomas visuales y mareos, presentando las pacientes con preeclampsia grave un mayor número de síntomas, seguido por las pacientes con preeclampsia leve e hipertensión gestacional. Las pacientes con embarazos normales no refirieron síntomas o signos patológicos, solo refirieron contracciones uterinas dolorosas (Figura 1B).

Los niveles séricos de amonio en pacientes con preeclampsia leve y preeclampsia grave fueron significativamente superiores al ser comparados con los niveles observados en las embarazadas sanas y en las embarazadas con hipertensión gestacional (Figura 2A), mientras que la actividad ADA en pacientes con preeclampsia leve, preeclampsia grave e hipertensión gestacional fue significativamente mayor $(p<0,05)$ en relación con el grupo de embarazadas sanas (Figura $2 \mathrm{~B}$ ).

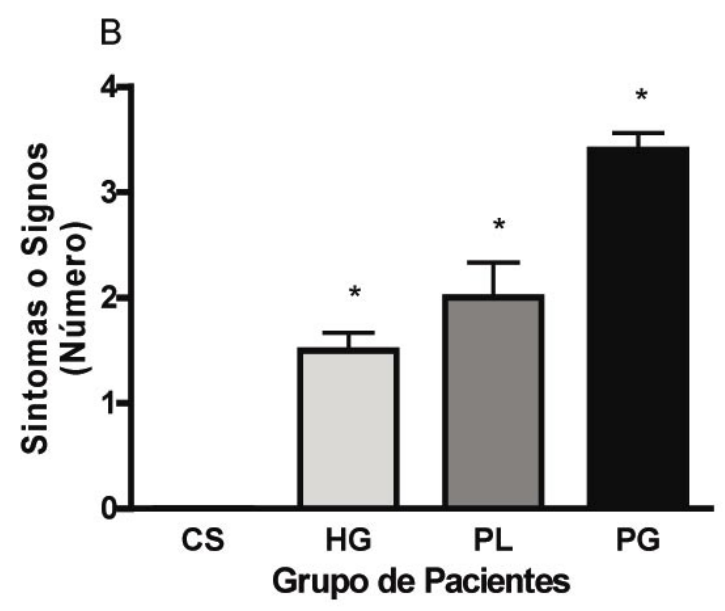

Figura 1B. Edad y clínica de los pacientes con embarazos normales y con trastornos hipertensivos.

En $B$ se muestra el promedio \pm EE de la frecuencia de síntomas o signos referidos o presentados por los pacientes, obsérvese que la frecuencia de la sintomatología se incrementa en función de la gravedad clínica del cuadro hipertensivo. * $p<0,05$ al ser comparados con CS (control sano).

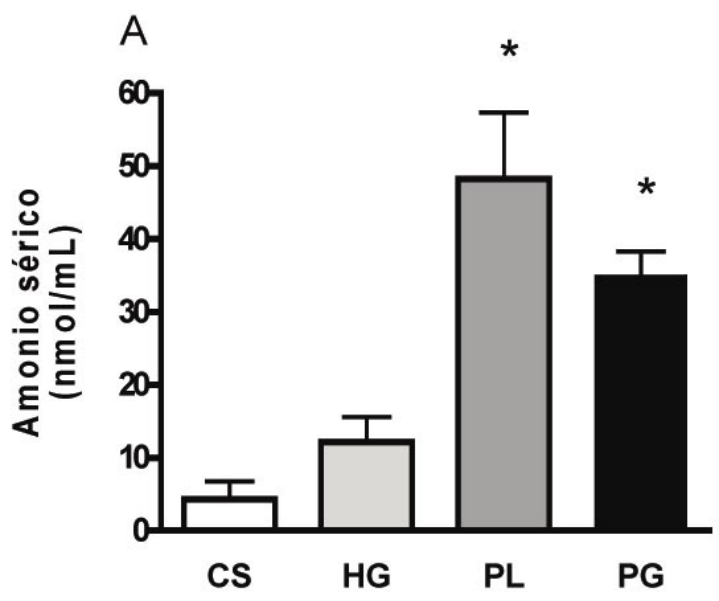

Grupos de pacientes

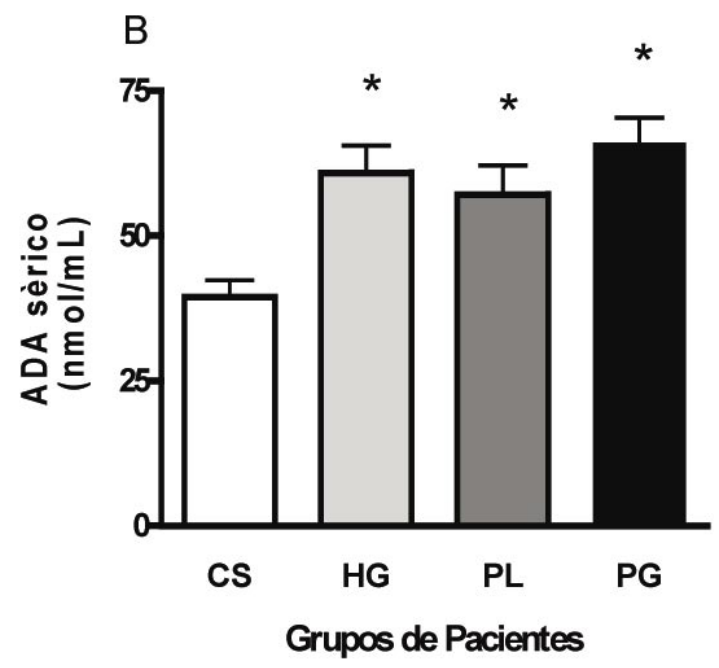

Figura 2. Niveles séricos de amonio y ADA en pacientes con trastornos hipertensivos del embarazo. En ambos gráficos se presenta el promedio $\pm \mathrm{EE}$ para cada grupo: control sano (CS), hipertensión gestacional $(\mathrm{HG})$, preeclampsia leve $(\mathrm{PL})$, preeclampsia grave $(P G)$. Se detectó una elevación significativa en los niveles séricos de amonio en pacientes con $P L$ y $P G$, comparados con las pacientes $C S$ y $H G(A)$, mientras que se encontraron niveles séricos de ADA elevados significativemente en pacientes con HG, PL y PG en comparación con CS (B). ${ }^{*} p<0,05$ al ser comparados con CS.

Al analizar la relación de los niveles de ADA con otros marcadores bioquímicos observamos que los niveles de esta enzima se correlacionaron positivamente con la creatinina y el ácido úrico sérico 
(Figura 3A y 3B), de igual manera se observó una correlación positiva entre los niveles séricos de $\mathrm{AU}$ y los niveles séricos de creatinina (Figura 4A). Los niveles séricos de TGO, TGP, LDH se elevaron significativamente en la pre-eclampsia grave, mientras, que los niveles de ácido úrico (AU) se elevaron significativamente en función de la gravedad clínica (Tabla I, Figura 4B).
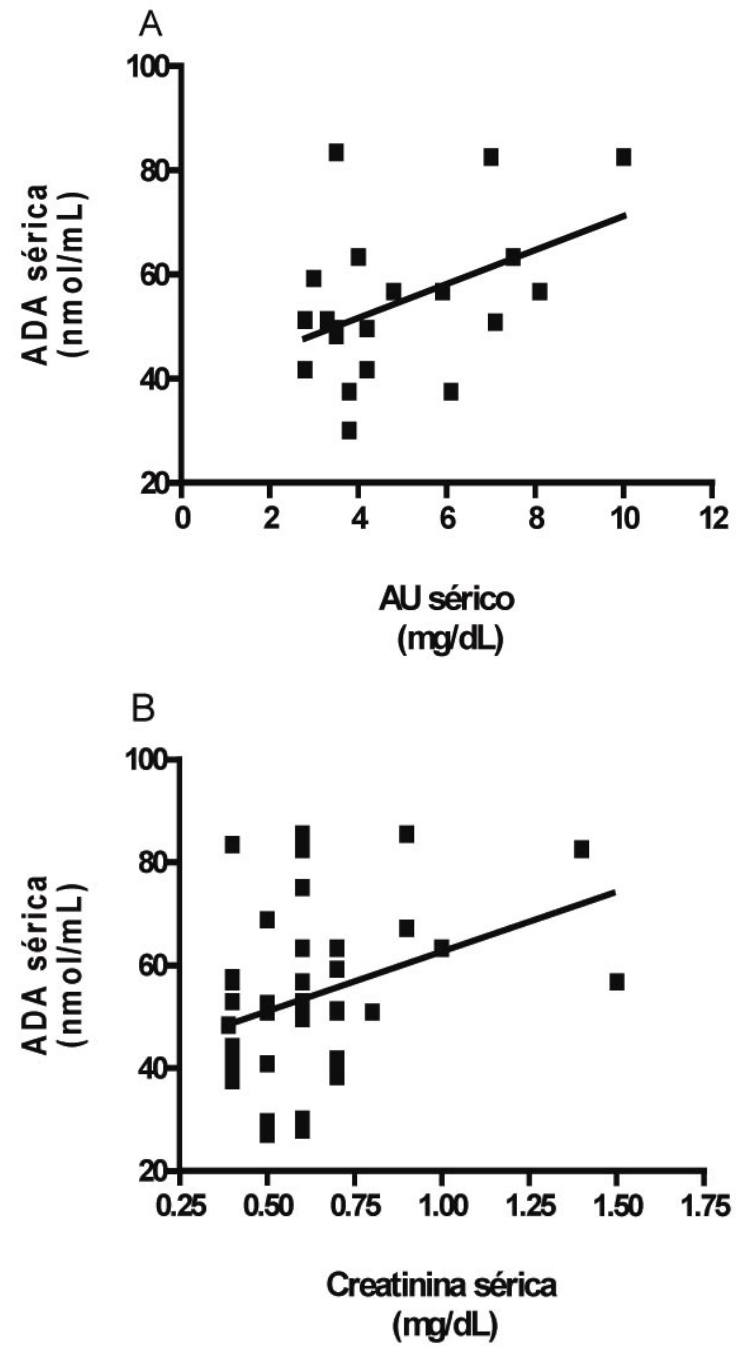

Figura 3. Correlación entre los niveles séricos de ADA con respecto a AU y creatinina sérica. Hubo correlación significativa entre los niveles de $A U$ y ADA (A) en pacientes con HG, PL y PG ( $r$ de Pear$\left.s o n=0,44 ; p=0,04 ; r^{2}=0,20\right)$. Hubo correlación significativa entre los niveles de creatinina y ADA (B) en pacientes con $\mathrm{HG}, \mathrm{PL}$ y $\mathrm{PG}$ ( $r$ de Pearson $=0,36$, $\left.p=0,02, r^{2}=0,13\right)$.

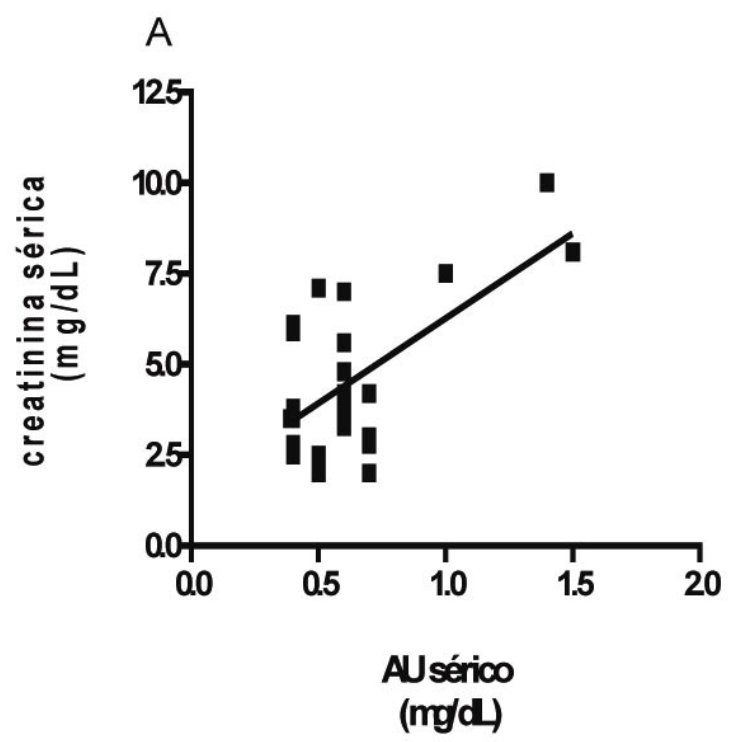

B

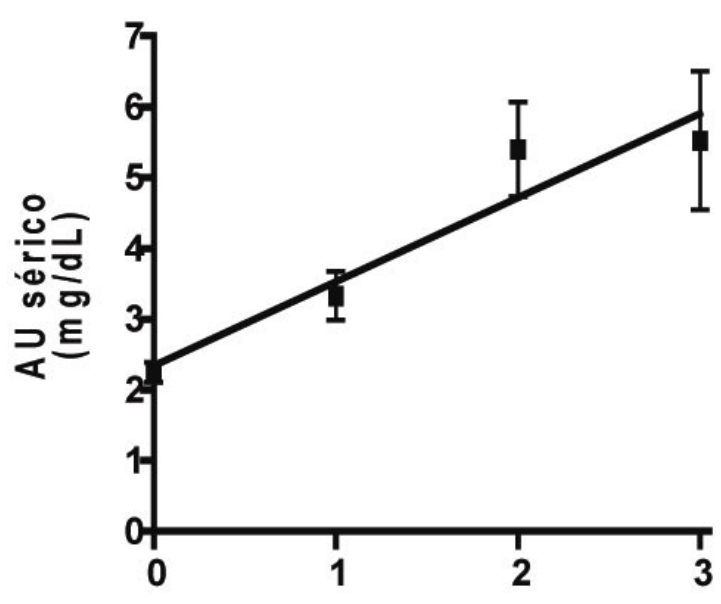

\section{Nivel de Severidad}

Figura 4. Relación entre los niveles séricos de AU con la severidad del cuadro hipertensivo y los niveles séricos de creatinina. Se observó una correlación significativa entre los niveles creatinina y $A U$ en pacientes con HG, PL y PG ( $r$ de Pearson $=0,63$; $\left.p=0,0006 ; r^{2}=0,40\right)$. En $B$ se observa la correlación entre los promedios de niveles séricos de $A U$ en cada grupo de pacientes con la severidad de los trastornos hipertensivos, observándose un incremento en los niveles séricos de $A U$ en relación a la evolución de los trastornos hipertensivos ( $\mathrm{r}$ de Pearson $\left.=0,95 ; r^{2}=0,91 ; p=0,04\right)$. En B CS (0), HG (1), PL (2), PG (3). 


\section{DISCUSIÓN}

Nuestro estudio permite confirmar que los niveles séricos de la enzima adenosin deaminasa se encuentran elevados en la preeclampsia y para nuestro conocimiento se reporta por primera vez una elevación de los niveles de dicha enzima en la hipertensión gestacional y una correlación positiva entre los niveles de ADA con los niveles de ácido úrico y de creatinina.

Yoneyama y cols $(6,7,11)$, demostraron en pacientes con preeclampsia, la existencia de niveles séricos elevados de ADA con predominio de la isoforma 2, de niveles elevados de malondialdehído (MDA), en la proporción de células productoras de IFN-y, en el número de monocitos en sangre periférica y de los niveles séricos de neopterina, mientras que observaron una disminución de la proporción de células productoras de IL-4, y asociaron los hallazgos a un incremento en la peroxidación lipídica y a un incremento en la respuesta inmune mediada por células. Karabulut y cols (8), confirmaron el incremento de los niveles séricos de ADA y MDA en la preeclampsia, concomitantemente con el incremento de la enzima xantino-oxidasa, sugiriendo a ADA y MDA como marcadores de desórdenes inmunológicos y de estrés oxidativo, respectivamente. Sin embargo, Kolusari y cols (12), a pesar de detectar niveles elevados de ADA, encontraron niveles significativamente disminuidos de la catalasa eritrocitaria, indicando que en la preeclampsia están favorecidos los fenómenos oxidativos. Al igual que lo reportado por Kafkasli y cols (9), en este estudio no se logró observar correlación entre los niveles séricos de ADA y la severidad de la enfermedad.

El incremento en los niveles séricos de ADA podría deberse a un mecanismo compensatorio como consecuencia de la elevación de los niveles de adenosina (5). La elevación de los niveles de adenosina ha sido demostrada en los pacientes con preeclampsia (13), y han sido relacionados con un incremento de la síntesis y liberación de adenosina estimulada por la hipoxia (14), o por un rápido recambio celular producto del remodelamiento vascular (15). La hipoxia es un fenómeno placentario o generalizado producido por la inflamación endotelial y los fenómenos vasoconstrictores inducidos por mediadores hormonales e inflamatorios (16). Eltzschig y cols (5), encontraron que la actividad ADA fue incrementada en un modelo murino de hipoxia aguda y en pacientes con hipoxia crónica, lo que provee un importante mecanismo de balance extracelular de los niveles de adenosina en condiciones de un elevado recambio en el metabolismo del nucleótido adenina.
La elevación de los niveles de ADA, como reflejo de la activación de la ruta metabólica de degradación de las purinas, es sugerido en este trabajo al demostrar una correlación entre los niveles ácido úrico $(\mathrm{AU})$ y la actividad de ADA, concepto sustentado en los datos de autores que han demostrado en pacientes con preeclampsia un incremento de la actividad de la enzimas 5-nucleotidasa (17) y xantino-oxidasa (8), enzimas responsables de la generación de adenosina y $A U$, respectivamente. Suzuki y cols (18), evaluaron los cambios en las concentraciones de adenosina y de xantina en el plasma fetal de ovejas, durante y posterior a una asfixia inducida por oclusión del cordón umbilical, encontrando efectivamente un aumento en los niveles de esas enzimas, las cuales regresaron a sus niveles basales al restaurar el flujo sanguíneo.

El $A U$ ha sido considerado un marcador que permite predecir la severidad de la preeclampsia (17), de la ocurrencia de retardo en el crecimiento intrauterino (19), de la evolución del feto y de la mortalidad perinatal (20), en consecuencia el AU es un elemento fundamental para tomar decisiones en el manejo de la paciente preeclámptica basándose en criterios realistas (21). En este trabajo observamos que la elevación de ese marcador se correlacionó con la gravedad de los procesos hipertensivos.

El AU al igual que la adenosina reflejan eventos de hipoxia, recientemente ha sido observado que los niveles séricos de AU se elevan durante la apnea del sueño y se correlacionan con la severidad de la hipoxia y con los niveles de adenosina (22). En este trabajo los niveles de $\mathrm{AU}$ se asociaron con los niveles de ADA, por lo tanto, la elevación de ADA pueden ser considerada marcador de hipoxia tisular. No obstante, el incremento de AU es reflejo de un flujo metabólico aumentado en la ruta de degradación de las purinas, también puede ser indicativo de un deterioro de la función renal. Esto es sugerido por nuestros resultados al observar que los niveles de AU y de ADA se correlacionan con los niveles de creatinina, sustentando la idea de una disminución en la filtración glomerular, sin embargo, la elevación de AU puede ser también refejo de un aumento de la reabsorción tubular de este compuesto (23).

El deterioro de la función renal es consecuencia de los fenómenos inflamatorios-edematosos del endotelio de los capilares renales y glomerulares, lo cual predispone a la hipoxia renal y a la elevación concomitante de los niveles de adenosina, quien causa vasoconstricción de las arteriolas aferentes, disminuyendo la presión de filtración glomerular, siendo este fenómeno ahorrador de las reservas energéticas al disminuir las especies filtradas, 
factibles de ser reabsorbidas mediantes mediante transportes activos que requieren ATP (24). La elevación de los niveles de adenosina producto de la isquemia renal induce la elevación de ADA, por lo tanto, esta enzima puede ser considerada al igual que la creatinina un marcador pronóstico de daño renal y de compromiso materno-fetal durante la preeclampsia.

La hiperamonemia es un fenómeno observado en la preeclampsia (25) y se puede relacionar con un balance nitrogenado negativo (26), o con un incremento de la degradación de las purinas. Sin embargo, a pesar que los niveles elevados de amonio se asociaron con la preeclampsia, no observamos su relación con los niveles de ADA, cuyos niveles se correlacionan con la actividad de la ruta metabólica de degradación de las purinas. Esta discrepancia podría ser resuelta asumiendo que el amonio producido por la placenta durante la hipoxia a través de la degradación de adenosina a ácido úrico, es eficientemente metabolizado a glutamina, la cual es utilizada por el feto para la síntesis de novo de nucleótidos (27), por lo tanto, los niveles elevados de amonio en la preeclampsia podrían reflejar un deterioro de la función hepática materna, reflejada en este estudio con los niveles elevados de la TGO, TGP y LDH.

Los altos niveles de ADA en los pacientes con hipertensión arterial gestacional observados en este estudio, sugieren que la enzima es un marcador para estados hipertensivos del embarazo, indicando que la hipertensión gestacional representa una etapa evolutiva de menor gravedad en la preeclampsia. Este punto de vista es sustentado porque del 15 al $45 \%$ de las pacientes con hipertensión gestacional evolucionan a preeclampsia (28), estos autores señalan que durante la hipertensión gestacional existe una hipoxia restringida a la placenta que puede evolucionar hasta la afectación hipóxica multisistémica, que comprometa la función renal y hepática, así mismo indican que la placenta isquémica es la principal fuente de adenosina.

\section{CONCLUSIÓN}

Este estudio presenta datos que permiten relacionar la actividad de ADA con los trastornos hipertensivos del embarazo, los niveles elevados de amonio con la preeclampsia y asociar los niveles de AU, TGO y LDH con la severidad de los trastornos hipertensivos.
Agradecimientos: Al Servicio IV de Ginecología y Obstetricia del Hospital Central Universitario Antonio María Pineda y al Consejo de Desarrollo Científico Humanístico y Tecnológico de la Universidad Centroccidental Lisandro Alvarado, que permitieron la realización de esta investigación.

\section{BIBLIOGRAFÍA}

1. Duley L. The global impact of preeclampsia and eclampsia. Sem Perinatol 2009;33:130-7.

2. Sibai BM. Diagnosis and management of gestational hypertension and preeclampsia. Obstet Ginecol 2003;102(1):181-92.

3. Ayuk PT, Matijevic R. Placental ischaemia is a consequence rather than a cause of pre-eclampsia. Med Hiphoteses 2006;67:792-5.

4. Ryzhov S, Zaynagetdinov R, Goldstein AE, Novitskiy SV, Dikov MM, Blackburn MR, et al. Effect of A2B adenosine receptor gene ablation on proinflammatory adenosine signaling in mast cells. J Immunol 2008;180:7212-20.

5. Eltzschig HK, Faigle M, Knapp S, Karhausen J, Ibla $\mathrm{J}$, Rosenberger $\mathrm{P}$, et al. Endothelial catabolism of extracellular adenosine during hypoxia: the role of surface adenosine deaminase and CD26. Blood 2006;108:1602-10.

6. Yoneyama $\mathrm{Y}$, Sawa R, Suzuki S, Otsubo Y, Miura A, Kuwabara $Y$, et al. Serum adenosine deaminase activity in women with preeclampsia. Gynecol Obstet Invest 2002;54:164-7.

7. Yoneyama Y, Sawa R, Suzuki S, Miura A, Kobayashi $\mathrm{H}$, Doi D, et al. Relation between adenosine deaminase activities and cytokine-producing $T$ cells in women with preeclampsia. Clin Biochem 2002;35:303-6.

8. Karabulut AB, Kafkash A, Burak F, Gozukara EM. Maternal and fetal plasma adenosine deaminase, xanthine oxidase and malondialdehyde levels in preeclampsia. Cell Bichem Funct 2005;23:279-83.

9. Kafkasli A, Karabulut AB, Atmaca R, Laurini R. Clinical correlation between adenosine deaminase activity and pre-eclampsia severity. J Int Med Res 2006;34:24755.

10. Giusti G, Galanti B. Colorimetric method. In methods of enzimatic analysis (Bergmeyer HU, Ed). Weinheim: Verlag Chemie 1984;315-23.

11. Yoneyama Y, Sawa R, Suzuki S, Doi D, Yoneyama $\mathrm{K}$, Otsubo Y. Relationship between plasma malondialdehyde levels and adenosine deaminase activities in pre-eclampsia. Clin Chem Acta 2002;322:169-73.

12. Kolusari A, Kurdoglu M, Bugdayci G, Adali E, Yildizhan $R$, Cebi $A$, et al. Relationship between erythrocyte catalase and serum adenosine deaminase activities in eclampsia. J Matern Fetal Neonatal Med 2009;22:321-4.

13. Yoneyama Y, Suzuki S, Sawa R, Yoneyama K, Power GG, Araki T. Increased plasma adenosine concentrations and severity of preeclampsia. Obstet Gynecol 2002;100:1266-70. 
14. Saito $H$, Nishimura M, Shinano H, Makita H, Tsujino I, Shibuya E, et al. Plasma concentration of adenosine during normoxia and moderate hypoxia in humans. Am J Respir Crit Care Med 1999;159:1014-8.

15. Roberts JM, Pearson GD, Cutler JA, Lindheimer M; National Heart Lung and Blood Institute. Summary of the NHLBI working group on research on hypertension during pregnancy. Hypertens Pregnancy 2003;22:10927.

16. Dekker GA. Risk factors for preeclampsia. Clin Obstet Gynecol 1999;42:422-35.

17. Yoneyama $Y$, Suzuki S, Sawa R, Otsubo $Y$, Miura A, Kuwabara $Y$, et al. Plasma 5'-nucleotidase activities and uric acid levels in women with pre-eclampsia. Gynecol Obstet Invest 2002;54:168-71.

18. Suzuki S, Yoneyama Y, Sawa R, Murata T, Araki T, Power G. Changes in fetal plasma concentrations during fetal asphyxia with maternal oxygen administration in ewes. J Exp Med 2000;192:275-81.

19. D'Anna R, Baviera G, Scilipoti A, Leonardi I, Leo R. The clinical utility of serum uric acid measurements in pre-eclampsia and transient hypertension in pregnancy. Panminerva Med 2000;42:101-3.

20. Varma TR. Serum acid uric levels as an index of fetal prognosis in pregnancies complicated by pre-existing hypertension and pre-eclampsia of pregnancy. Int $\mathrm{J}$ Gynaecol Obstet 1982;20:401-8.

21. Koopmans CM, Van-Pampus MG, Groen H, Aarnoud- se JG, Van den Berg PP, Mol BW. Accuracy of serum uric acid as a predictive test for maternal complications in pre-eclampsia: Bivariate meta-analysis and decision analysis. Eur J Obstet Gynecol Reprod Biol 2009;146:8-14.

22. Saito $H$, Nishimura M, Shibuya E, Makita H, Tsujino I, Miyamoto $\mathrm{K}$, et al. Tissue hypoxia in sleep apnea syndrome assessed by uric acid and adenosine. Chest 2002;122:1686-94

23. Oian P, Monrad-Hansen HP, Maltau JM. Serum uric acid correlates with beta 2-microglobulin in preeclampsia. Acta Obstet Gynecol Scand 1986;65:1036.

24. Vallon V, Mühlbauer B, Osswald H. Adenosine and Kidney Function. Physiol Rev 2006;86:901-40.

25. Li J, Sun J, Lu H. Determination of serum free amino acids and ammonia in pregnant women with severe pregnancy induced hypertension. Zhonghua Fu Chan Ke Za Zhi 1996;31:468-70.

26. Kam J, Kennedy JD, Dwyer EO. Serum enzymes and blood ammonium in hepatic disease of pregnancy. Ir J Med Sci 1962;441:413-22.

27. Self JT, Spencer TE, Johnson GA, Hu J, Bazer FW, Wu G. Glutamine synthesis in the developing porcine placenta. Biol Reprod 2004;70:1444-51.

28. Medina-Lomeli JM, Medina-Castro N. Diferencias y similitudes de la preeclampsia y la hipertensión gestacional. Ginecol Obstet Mex 2005;73:48-53. 